\title{
The Journal and the Rest of the World
}

\author{
Eelco F. M. Wijdicks
}

Published online: 5 January 2011

(C) Springer Science+Business Media, LLC 2011

Neurocritical Care is the official journal of Neurocritical Care Society-an international organization. The society is expanding its wings toward all countries and the journal is a reflection of that. Although the journal is US made and US maintained, scientific articles from countries of the world outside the US are omnipresent.

We like to think of ourselves as an international journal. What are arguments for that? First, our contributors are increasingly from outside the US. In 2009, more than 50\% of all total submissions were from multiple regions of the globe-36 countries to be more precise-with Germany taking the top spot. (This is not unexpected with the well organized Deutsche Gesellschaft für Neurointensiv und Notfallmedizin currently presided by Professor Stefan Schwab.)

Second, our editorial board has representatives from all continents and from many countries with active neurocritical care programs. Neurointensive care may not be as well organized in other countries due to financial constraints, lack of organizational structure and perhaps politics, but courses are abound and dedicated to the care of the critically ill neurologic patient. We can expect some significant catching up in the next decade.

Third, an introductory free 1 year membership is offered to major European critical care organizations. This is good for neurocritical care, good for international authors, and obviously good for the journal.

We also encourage articles from developing countries. Care of critically ill neurologic patients is the same everywhere although armed conflict may have increased traumatic head injury, spinal cord injury, and associated

E. F. M. Wijdicks ( $\square)$

Mayo Clinic, Rochester, USA

e-mail: wijde@mayo.edu
CNS infections. Meningococcal meningitis in countries with low vaccination rates are common and of our concern. We should be the first journal to present data on the management of the polio (or is it West-Nile?) epidemic in the republic of Congo. But we know too well that stroke, and stroke again are the most common acute neurologic problems in developing countries. We will be publishing articles addressing some of these major issues next year.

When we encourage authors from foreign countries to contribute, we recognize there is a longstanding problem with the English language. So how can international authors improve their chances? No editor will get encouraged by poorly written, poorly prepared articles and we do get them every once in a while. Writing articles is not only good data presentation, but also good and interesting English. We do like to assist and we try to avoid a biased peer review, but authors should find a native English speaker to help.

This editorial would be amiss not to look back on last year. For impact factor afficiados, we were pleased that our impact factor increased to 2.17 and has been rising steadily. Our submissions continue to grow at an annual 20-30\% rate while keeping the number of rejected articles to a bare-but necessary-minimum. If the number of submissions will continue to grow at this rate, we will move to eight issues a year and eventually monthly. This change may seem small, but the logistic problems are much greater and will have to be solved in order to proceed.

I cannot resist the temptation to relate why I believe we are on the radar screen. Our journal is clinically useful for neurointensivists, fellows and residents, and we have an unprecedented turn around time. We will continue to get good articles reviewed as quick as possible and no one should have to wait. We have been fortunate to publish randomized trials - an unmistaken luxury for a new 
journal-and we appreciate it that authors send us their best material. What has been very encouraging is that our full text downloads-an accurate indicator of the actual journal usage had a $100 \%$ increase from last year and now nearly at 80.000 downloads. Looking at another measure, the number of people registered to receive ToC Alerts journal grew by $30 \%$.

I encourage our readers to submit video clips with their manuscripts and we continue to welcome scholarly review papers on common day-to-day problems.
Every year we will introduce new features to the journal and for this year we will introduce a neuroscience nursing section.

Again, I thank the members of the editorial board, the ad hoc reviewers listed below (marked with an asterisk denotes 3 or more reviews), and the editorial team at Springer (Benjamin Ellis and Srilakshmi Patrudu). You have my gratitude.

\section{Ad Hoc Reviewers 2010}

\begin{tabular}{|c|c|c|}
\hline Abend, Nicholas & Dhar, Rajat* & Josephson, S. Andrew \\
\hline Adeoye, Opeolu* & Diaz, Victor & Kamath, Sriganesh \\
\hline Aisiku, Imoigele & Dohmen, Christian & Kaneko, Tadashi \\
\hline Akins, Paul & Dreier, Jens & Kapapa, Thomas \\
\hline Andrade, Fabio & Eddleman, Christopher & Kapinos, Gregory \\
\hline Bakar, Bulent & Edlow, Jonathan & Kastrup, Oliver \\
\hline Bandyopadhyay, Saikat & Fields, Jeremy* & Katsaridis, Vasilios \\
\hline Baskaya, Mustafa & Fink, Ericka & Keyrouz, Salah* \\
\hline Baumann, Antoine & Flaherty, Matthew & Klein, Matthias \\
\hline Beer, Ronny* & Fletcher, Jeffrey & Knezevic, Nebojsa Nick \\
\hline Bell, Michael* & Flint, Alexander & Koenig, Matthew \\
\hline Bell, Randy & Fragata, Isabel* & Kofke, W. Andrew \\
\hline Bershad, Eric* & Freeman, William & Kollmar, Rainer \\
\hline Bilotta, Federico & Fugate, Jennifer & Kolls, Bradley \\
\hline Bledsoe, Kathleen & Furtado, Sunil & Kramer, Andreas \\
\hline Bloomfield, Eric & Gasco-Tamarit, Jaime & Kuluz, John* \\
\hline Bojanowski, Michel & Gaul, Charly & Kumar, Avinash \\
\hline Bourekas, Eric & Ghaly, Ramsis & Lackner, Peter* \\
\hline Brown, Jules* & Giraldo, Elias & Lansberg, Maarten \\
\hline Burns, Joseph* & Godoy, Daniel & Lascola, Christopher \\
\hline Campbell, Peter & Goldstein, Joshua* & Latorre, Julius Gene \\
\hline Carandang, Raphael & Griesdale, Donald & Layton, Kennith \\
\hline Carpenter, Jessica & Halperin, John* & Lazaridis, Christos \\
\hline Carrera, Emmanuel & Hansen-Schwartz, Jacob & Lee, Kiwon \\
\hline Castellani, Gianluca & Hashimoto, Tomoki & Legriel, Stephane \\
\hline Chen, Jeff & Hays, Angela & Lescot, Thomas \\
\hline Chiang, Veronica & Helbok, Raimund & Levine, Joshua \\
\hline Chieregato, Arturo & Henry-Lagarrigue, Matthieu & Liang, Cheng-Loong \\
\hline Choi, Hye-Yeon & Hill, Michael & Liebeskind, David \\
\hline Colbourne, Frederick & Huff, J. Stephen* & Ling, Geoffrey \\
\hline Coles, Jonathan & Hui, Ferdinand & Llompart-Pou, Juan \\
\hline Conti, Alfredo* & Human, Theresa* & Lodi, Yahia \\
\hline Cordina, Steve & Hurdle, April* & Marino, Silvia \\
\hline Corry, Jesse* & Jacob, Jeffrey & McLaughlin, Nancy \\
\hline Cruz-Flores, Salvador* & Jaeger, Matthias & Mertes, Paul Michel \\
\hline Danielisova, Viera & James, Michael* & Meyer, Phillippe \\
\hline de Oliveira, Jean & Janjua, Tariq* & Miller, Chad \\
\hline
\end{tabular}


Mink, Susanne

Moussouttas, Michael*

Muehlschlegel, Susanne*

Nagayama, Masao*

Naidech, Andrew*

Nakagawa, Kazuma

Nam, Hyo Suk

Nanchal, Rahul

Nates, Joseph

Neyens, Ron

Nguyen, Thanh

Nuwer, Marc

Nyquist, Paul*

Oddo, Mauro

Orakcioglu, Berk

Padilla, Juan

Paterakis, Konstantinos

Popugaev, Konstantin

Provencio, J. Javier
Puppo, Corina

Pyne-Geithman, Gail

Rincon, Fred

Rossetti, Andrea

Sarrafzadeh, Asita

Schirmer, Clemens*

Schwarz, Stefan

Scott, L. Keith

Seder, David*

Sedy, Jiri

Shutter, Lori*

Silver, Brian

Sims, John

Singh, Vineeta

Smith, Martin

St. Louis, Erik

Stein, Sherman

Steiner, Luzius

Sykora, Marek
Tabarki, Brahim

Tawil, Isaac

Taylor, Robert

Tisherman, Samuel*

Torbey, Michel*

van de Beek, Diederik

van den Bergh, Walter

van der Worp, Hendrik

Wafaisade, Arasch

Wang, David

Wang, Marjorie

Weiss, Nicolas*

Wendell, Linda

White, James

Wiwanitkit, Viroj

Zada, Gabriel

Zazulia, Allyson

Ziai, Wendy*

Zubkov, Alexander* 